\title{
PENTINGNYA DIAGNOSA KEPERAWATAN SERTA TIPE-TIPE DALAM PERSYARATAN DIAGNOSA KEPERAWATAN UNTUK PASIEN \& PERAWAT
}

\section{TATI OKTIANA TAMBA}

\author{
Tatitamba26@gmail.com
}

\section{LATAR BELAKANG}

Diagnosa keperawatan merupakan langkah kedua dari proses keperawatan yang menggambarkan penilaian klinis tentang respon individu, keluarga, kelompok maupun masyarakat terhadap permasalahan kesehatan baik aktual maupun potensial. Dimana perawat mempunyai lisensi dan kompetensi untuk mengatasinya.

Diagnosa keperawatan adalah pernyataan yang menguraikan respons aktual dan potensial klien terhadap masalah kesehatan yang perawat mempunyai ijin dan berkompeten untuk mengatasinya. Respon aktual dan potensial klien didapatkan dari data dasar pengkajian, tinjauan literatur yang berkaitan, catatan medis klien masa lalu dan konsultasi dengan profesi lain yang kesemuanya itu dikumpulkan selama pengkajian. Hal terakhir adalah respon aktual dan potensial klien yang membutuhkan intervensi dari domain praktik keperawatan (Carlson et al, 1991, Carpenito, 1995). Tujuan Kajian ini dibuat untuk meningkatkan pengetahuan perawat bahwa proses keperawatan itu sangat penting terutama dalam diagnosa pasien.

Setiap diagnosis keperawatan memiliki label dan definisi yang jelas. Hal ini penting untuk menyatakan bahwa apakah label atau daftar label yang ada tidak mencukupi. Sangat penting bahwa perawat mengetahui definisi diagnosis yang paling sering mereka gunakan. Selain itu, mereka perlu mengetahui "indikator diagnostik"-data yang digunakan untuk mendiagnosis dan untuk membedakan satu diagnosis dari yang lain. Tndikator diagnostik meliputi batasan karakteristik dan faktor yang berhubungan atau faktor risiko. Batasan karakteristik adalah tanda/kesimpulan yang dapat diamati yang dikelompokkan sebagai manifestasi dari diagnosis (mis., tanda atau gejala). Pengkajian yang mengidentifikasi adanya sejumlah karakteristik memberikan dukungan terhadap ketepatan diagnosis keperawatan. Faktor yang berhubungan merupakan komponen integral dari semua diagnosis keperawatan yang berfokus-masalah. Faktor 
yang berhubungan dengan penyebab, keadaan, fakta, atau pengaruh yang memiliki beberapa jenis hubungan dengan diagnosis keperawatan (mis, penyebab, faktor yang berkaitan).

Pada saat pengkajian, perawat perlu memperhatikan dan mempertimbangkan proses kesehatan apa yang sedang berlangsung pada diri klien. Karena dengan memperhatikan perilaku klien dalam menyelesaikan suatu proses akan mempermudah perumusan diagnosa keperawatan. Apabila suatu proses terjadi, klien harus dapat menyelesaikan sejumlah tahapan sebelum mencapai sasaran. Dengan mengidentifikasi perilaku dan langkah yang dilakukan oleh klien, perawat dapat menilai kemajuan dalam menyelesaikan proses dan menggunakan informasi tersebut untuk merumuskan diagnosa keperawatan.Tujuan Kajian tipe-tipe diagnosa keperawatan yang penting diketahui oleh perawat dan mahasiswa keperawatan bertujuan untuk mengetahui defenisi diagnosa keperawatan dan untuk mengetahui tipe-tipe diagnosa keperawatan menurut beberapa ahli serta untuk memperluas pengetahuan para pembaca secara khusus perawat dan mahasiswa keperawatan.

\section{METODE}

Metode yang dilakukan yaitu literature review, yaitu dengan menganalisa buku-buku dan jurnal yang berkaitan tentang pentingnya diagnosa keperawatan untuk pasien,perawat dan mahasiswa keperawatan.Dan Literature review ini melakukan analisa dan kajian bebas terhadap artikel, jurnal, text book, maupun ebook yang sesuai dan berfokus pada tipe-tipe diagnosa keperawatan yang penting diketahui oleh perawat dan mahasiswa keperawatan. Menggunakan jurnal dengan terbitan 2012 tahun terakhir.

\section{HASIL}

Diagnosa keperawatan merupakan keputusan klinik tentang respon individu, keluarga dan masyarakat tentang masalah kesehatan aktual atau potensial, dimana berdasarkan pendidikan dan pengalamannya, perawat secara akuntabilitas dapat mengidentifikasi dan memberikan intervensi secara pasti untuk menjaga, menurunkan, membatasi, mencegah dan merubah status kesehatan klien (Herdman, 2012) Diagnosa keperawatan menurut Carpenito (2001) dapat di bedakan menjadi diagnosa keperawatan syndrome dan kolaborasi. Sedangkan menurut Herdman (2012) diagnosa keperawatan dapat dibedakan menjadi diagnosa keperawatan aktual, resiko, kemungkinan, dan kesejahteraan. 
Jika perawat mampu merumuskan diagnosa sesuai dengan data-data pengkajian, dapat meningkatkan asuhan keperawatan dengan baik dan tercapailah tujuan perawat untuk meningkatkan keakuratan diagnosa dalam asuhan keperawatan, tercapai tujuan perawat dan meningkatkan kesehatan pasien. Hasil dari pengkajian ini adalah setelah dilakukan pengkajian menggunakan metose literatur review mengenai tipe tipe diagnosa dapat disimpulkan bahwa pembaca dapat membedakan setiap jenis atau tipe diagnosa sehingga mempermudah bagi pembaca untuk melakukan atau memilih diagnosa berdasarkan dengan khasus pasien.

Hasil yang diharapkan yaitu, kita sebagai perawat tahu mengenai apa itu diagnosa keperawatan yang pentingnya diagnosa keperawatan untuk memberikan asuhan yang sesuai dengan kebutuhan klien. Dan untuk mengetahui bagaimana cara untuk menentukan diagnosa keperawatan.

\section{PEMBAHASAN}

Diagnosa keperawatan adalah pernyataan yang menguraikan respons actual atau potensial klien terhadap masalah kesehatan yang perawat mempunyai izin dan berkompeten untuk mengatasinya. Diagnosa keperawatan berhubungan dengan fungsi mandiri keperawatan, yaitu area unik dari pekerjaan perawat yang terpisah dengan medis.

Jenis (type) Diagnosa Keperawatan

1.Diagnosa actual adalah pertimbangan tentang respons klien terhadap masalah kesehatan yang ada pada waktu sekarang pada pengkajian perawat. Diagnosa keperawatan yang actual berdasarkan adanya tanda dan gejala yang berhubungan.

Contoh: pola nafas tidak efektif atau kecemasan.

2.Diagnosa potensial atau risiko keperawatan, seperti didefinisikan oleh NANDA, diagnose potensial adalah pertimbangan klinik bahwa klien lebih rentan untuk timbulnya masalah daripada orang lain pada situasi yang sama.

Contoh :Seorang perawat membuat diagnose risiko terjadi infeksi pada pasien onkologi yang menerima terapi radiasi yang masuk kerumah sakit karena pendarahan gastrointestinal. 
3.Kemungkinan Diagnosa Keperawatan adalah satu dari kenyataan tentang masalah kesehatan yang tidak jelas atau factor penyebab yang tidak diketahui. Kemungkinan diagnose memerlukan lebih banyak data untuk mendukung atau menghilangkannya.

Contoh :perawat memilih diagnose kemungkinan isolasi sosial untuk klien yang masuk kerumah sakit dengan diagnosa AIDS berhubungan dengan yang tidak ada pengunjung atau telepon.

4.Diagnosa sehat adalah sesuatu yang menunjukkan respons sehat dari klien yang menginginkan tingkat kesehatan yang lebih tinggi.

Contoh :potensial peningkatan parental

Identifikasi masalah : Sebelum merusmuskan diagnose keperawatan dilakukan identifikasi masalah. Masalah harus ditentukan secara spesifik agar intervensi yang diberikan tepa tsasaran. Masalah ditentukan apakah actual atau potensial.

Membuat Rumusan Diagnosa : Bentuk dasar format untuk pernyataan diagnostic adalah masalah yang berhubungan dengan etiologi, perawat harus mampu, menulis satu, dua, tiga dan empat bagian pernyataan diagnostik, demikian juga beberapa variasi dari masing-masing.

1.Pernyataan dua bagian :

- Masalah $(\mathrm{P}:$ Problem $)=$ >pernyataan respons klien

- Etiologi $(\mathrm{E})$ = >faktor-faktor yang berkontribusi sebagai penyebab dari respons

2.Pernyataan tiga bagian

Tiga bagian pernyataan diagnosis keperawatan disebut format PES yang mencangkup :

- Masalah ( P )

- Etiologi ( E )

- Tanda \& gejala ( $\mathrm{S}$ : symptom ) 
Karakteristik penentu yang dimanifestasikan oleh klien. Pentingnya diagnosa bagi perawat adalah perawat dapat mengetahui lebih detail masalah kesehatan pasien, respon-respon pasien, perawat juga harus berkolaborasi untuk menentukan diaonosis pasien sehingga dapat mengetahui lebih detail masalah kesehatan pasien.

Diagnosa juga penting untuk pasien karena dengan perawat melakukan diagnosa dengan berkolaborasi pasein dapat cepat sembuh lebih cepat, pasien juga akan merasakan kenyamanan, keamanan serta dapat mempercayai perawat dalam kesembuhan pasien.

Diagnosa keperawatan adalah pernyataan yang menggambarkan respons aktual atau potensial klien terhadap masalah kesehatan yang perawat mempunyai lisensi dan kompeten untuk menanganinya (Potter \& Perry : 2005). Diagnosis keperawatan adalah penilaian klinis tentang respons manusia terhadap gangguan kesehatan / proses kehidupan, atau kerentanan terhadap respons tersebut seorang individu, keluarga, kelompok atau komunitas (NANDA-I 2013 dalam NANDA-I 2018-2020). Diagnosis keperawatan biasanya berisi 2 bagian, yaitu : (1) Deskriptor atau pengubah ; dan (2) Fokus diagnosis atau konsep kunci dari diagnosis. Diagnosis berfokus masalah tidak boleh selalu dipandang lebih penting daripada diagnossi resiko. Karena bisa saja diagnosis resiko dapat menjadi diagnosis dengan prioritas tertinggi bagi pasien.

Sangat penting bagi perawat untuk mengetahui "indikator diagnostik data" yang digunakan untuk mendiagnosis dan untuk membedakan antara diagnosis yang satu dengan yang lain. Indikator diagnosis meliputi batasan karakteristik dan faktor yang berhubungan atau faktor resiko. Batasan karakteristk adalah tanda atau kesimpulan yang dapat diamati dan dikelompokkan sebagai manifestasi dari diagnosis. Pengkajian yang mengidentifikasi adanya beberapa karakteristik dapat menjadi acuan ketepatan diagnosis keperawatan. Faktor yang berhubungan adalah konponen intergral dari semua diagnosis keperawatan yang berfokus masalah. Faktor yang berhubungan dengan penyebab, keadaan, fakta atau pengaruh yang memiliki beberapa jenis hubungan dengan diagnosis keperawatan. Faktor resiko adalah pengaruh yang meningkatkan kerentanan individu, keluarga, kelompok atau masyarakat pada kondisi yang tidak sehat (NANDA-I 2018-2020). Proses diagnosis keperawatan memadukan keterampilan berpikir kritis dalam langkah - langkah pembuatan keputusan keperawatan untuk mengembangkan pernyataan diagnosis. Hal ini menyangkut analisis dan interprestasi data pengkajian, identifikasi masalah dan merumuskan masalah. Dalam proses diagnostik 
keperawatan terkadang dapat terjadi kessalahan - kesalahan . adapun beberapa sumber kesalahan itu terjadi karena : kesalahan dalam pengumpulan data, kesalahan dalam interpretasi dan analisis data, kesalahan dalam pengelompokan data dan kesalahan dalam pernyataan diagnostik. Diagnosa keperawatan memiliki keterbatasan, dan praktisi pemula harus menyadari tentang keberadaannya. Bahasa dari diagnosis dan yang tidak tepat dan terkadang bertele - tele dapat menyebabkan ketidaktepatan pemberian label pada klien.

Tipe diagnosa keperawatan menurut Carpenito (2009) dan Herdman (2012) sebagai berikut:

1. Aktual Aktual suatu diagnosa keperawatan yang menggambarkan penilaian klinis yang harus di validasi oleh perawat karena adanya batasan karakteristik mayor. Jenis keperawatan tersebut memiliki empat komponen : dimulai dari label, defenisi, karakteristik dan faktor yang berhubungan. Label yang di berikan juga harus singkat dan jelas, hal itu bertujuan untuk mempermudah dalam membantu membedakan diagnosa yang ada agar dapat di bedakan antara diagnosa yang satu dengan diagnosa yang lainnya.

2. Resiko Diagnosa keperawatan resiko menggambarkan penilaian klinis dimana individu maupun kelompok lebih rentan mengalami masalah yang sama di bandingkan orang lain di dalam situasi yang sama atau serupa. Syarat untuk

menegakkan diagnosa resiko ada unsur PE (Problem and Etiologi) dan untuk penggunaan batasan karakteristik yaitu "resiko dan resiko tinggi " tergantung dari tingkat kerentanan/keparahan suatu masalah. Dan faktor yang terkait untuk diagnosa keperawatan resiko merupakan faktor yang sama dengan keperawatan aktual seperti yang sudah dibahas sebelumnya di diagnosa keperawatan actual.

3. Kemungkinan Diagnosa kemungkinan adalah diagnosa keperawatan yang memerlukan data tambahan, hal tersebut bertujuan untuk mencegah timbulnya suatu diagnosa yang bersifat sementara, dan dalam menentukan suatu diagnosa keperawatan yang bersifat sementara bukanlah menunjukan suatu kelemahan atau keraguan dalam menentukan suatu diagnosa, akan tetapi merupakan suatu proses penting dalam keperawatan.

\section{Kesejahteraan}


Diagnosa keperawatan kesejahteraan merupakan penilaian klinis tentang keadaan individu, keluarga atau masyarakat dalam transisi dari tingkat sejahtera tertentu menjadi tingakat sejahtera yang lebih tinggi (Herdman, 2007).

5. Syndrome Diagnosa syndrome merupakan kumpulan gejala diagnosa keperawatan, karena terdiri dari diagnosa keperawatan aktual dan resiko yang di perkirakan ada karena situasi atau peristiwa tertentu. Berdasarkan peraturan menteri kesehatan Republik Indonesia nomor 40 tahun 2017 menyatakan bahwa salah satu kompetensi perawat adalah merumuskan diagnosa keperawatan.

\section{PENUTUP}

Diagnosa keperawatan ditetapkan berdasarkan analisis dan interpretasi data yang diperoleh dari pengkajian keperawatan klien. Diagnose keperawatan memberikan gambaran tentang masalah atau status kesehatan klien yang nyata (aktual) dan kemungkinan akan terjadi, dimana pemecahannya dapat dilakukan dalam batas wewenang perawat. Perawat dapat bekerja dengan professional dalam menjalankan tugas dan kewajiban sebagai seorang tenaga kesehatan yang bertanggung jawab. Sehingga, klien dapat merasakan kepuasan atas asuhan keperawatan yang diberikan.Tipe-tipe diagnosa keperawatan yang penting diketahui oleh perawat dan mahasiswa keperawatan yaitu : Aktual, Resiko, Kemungkinan, Kesehjateraan, Syndrome. Bagi perawat yang bertugas di rumah sakit sebagai pemberi asuhan keperawatan kepada pasien harus membuat diagnosa keperawatan yang benar dan jelas disertai dengan data-data dan informasi yang ada.

\section{DAFTAR PUSTAKA}

Bandiyah, S. (2017). Keterampilan Dasar dalam Keperawatan (KDDK). Yogyakarta: Nuha Medika

Bararah, Taqiyyah. 2013. Asuhan Keperawatan Panduan Lengkap Menjadi Perawat Profesional Jilid 1. Jakarta: Prestasi Pustaka.

Carpenito, L. J. (2013). Buku Saku Diagnosis Keperawatan. (E. Tiar, Ed.) (13th ed.). Jakarta: EGC. 
Herdman, T. Heather. (2018). NANDA-I Diagnosis Keperawatan : Definisi dan Klasifikasi 2018 - 2020, Ed :11. Jakarta : Penerbit Buku Kedokteran EGC

NANDA. (2015). Buku diagnosa keperawatan definisi dan klasifikasi 2015-2017. Jakarta: EGC NANDA. (2012). Panduan Diagnosa Keperawatan (Terjemahan). Jakarta: EGC.

Nanda International, 2018. Nursing Diagnosa: Defenition \& classification 2018-2020, Penerbit Buku Kedokteran: EGC

Simamora, R. H., Bukit, E., Purba, J. M., \& Siahaan, J. (2017). Penguatan kinerja perawat dalam pemberian asuhan keperawatan melalui pelatihan ronde keperawatan di rumah sakit royal prima medan. Jurnal pengabdian kepada masyarakat, 23(2), 300-304.

Simamora, R. H. (2019). Socialization of Information Technology Utilization and Knowledge of Information System Effectiveness at Hospital Nurses in Medan, North Sumatra. Editorial Preface From the Desk of Managing Editor..., 10(9).

Wilkinson, J., \& Ahern, n. R. (2013). Buku Saku Diagnosis keperawatan edisi 9 Diagnosis NANDA, Intervensi NIC, Kriteria hasil NOC. Jakarta: EGC.

Wirdah, H. (2016). Penerapan Asuhan Keperawatan Oleh Perawat Pelaksana di Rumah Sakit Banda Aceh. Jurnal Ilmiah Mahasiswa Fakultas Keperawatan, 1, 1-6.

Yeni Fitra. (2014). Pengaruh Pelatihan Proses Keperawatan terhadap Dokumentasi Asuhan Keperawatan di Puskesmas Kabupaten Agam Provinsi Sumatera Barat. Ners Journal Keperawatan Volume 10, No1. 